Elucidating Batch-to-batch Variation Caused by Homocoupled Side Products in Solution Processable Organic Solar Cells

Peer-reviewed author version

VANGERVEN, Tim; VERSTAPPEN, Pieter; Patil, Nilesh; D'HAEN, Jan;

CARDINALETTI, Ilaria; Benduhn, Johannes; Van den Brande, Niko; Defour, Maxime; Lemaur, Vincent; Beljonne, David; Lazzaroni, Roberto; Champagne, Benoît; VANDEWAL, Koen; Andreasen, Jens W.; ADRIAENSENS, Peter; Breiby, D.B.; Van Mele, Bruno; VANDERZANDE, Dirk; MAES, Wouter \& MANCA, Jean (2016) Elucidating Batch-to-batch Variation Caused by Homocoupled Side Products

in Solution Processable Organic Solar Cells. In: Chemistry of materials, 28(24), p. 9088-9098.

DOI: $10.1021 /$ acs.chemmater.6b04143

Handle: http://hdl.handle.net/1942/23110 


\title{
Elucidating Batch-to-Batch Variation Caused by Homocoupled Side Products in Solution Processable Organic Solar Cells
}

\author{
Tim Vangerven*†, Pieter Verstappen ${ }^{\ddagger}$, Nilesh Patil§, Jan D’Haen ${ }^{\dagger}$, Ilaria Cardinaletti ${ }^{\dagger}$, Johannes
}

Benduhn ${ }^{\nabla}$, Niko Van den Brande ${ }^{\phi}$, Maxime Defour ${ }^{\phi}$, Vincent Lemaur ${ }^{+}$, David Beljonne ${ }^{+}$, Roberto Lazzaroni $^{+}$, Benoit Champagne ${ }^{\#}$, Koen Vandewal ${ }^{\nabla}$, Jens W. Andreasen $\|$, Peter Adriaensens ${ }^{\ddagger}$, Dag W. Breiby§, Bruno Van Mele ${ }^{\phi}$, Dirk Vanderzande ${ }^{\ddagger}, \cap$, Wouter Maes ${ }^{\ddagger}$ and Jean Manca ${ }^{\square}$

${ }^{\dagger}$ Material Physics Division, Institute for Materials Research (IMO-IMOMEC), Hasselt University, Universitaire Campus Wetenschapspark 1, 3590 Diepenbeek, Belgium

$\ddagger$ Design \& Synthesis of Organic Semiconductors (DSOS)/Nuclear Magnetic Resonance spectroscopy group (NMR), Institute for Materials Research (IMO-IMOMEC), Hasselt University, Universitaire Campus - Agoralaan 1, 3590 Diepenbeek, Belgium

$\S$ Department of Physics, Norwegian University of Science and Technology (NTNU), Høgskoleringen 5, 7491 Trondheim, Norway

${ }^{\nabla}$ Dresden Integrated Center for Applied Physics and Photonic Materials (IAPP) and Institute for Applied Physics, Technische Universität Dresden, George-Bähr-Str. 1, 01069 Dresden, Germany

$\Phi$ Physical Chemistry and Polymer Science, Materials and Chemistry, Faculty of Engineering, Vrije Universiteit Brussel, Pleinlaan 2, 1050 Brussels, Belgium

${ }^{+}$Laboratory for Chemistry of Novel Materials, Université de Mons (UMONS), Place du Parc 20, 7000 Mons, Belgium

\# Department of Chemistry, Université de Namur (UNamur), Rue de Bruxelles 61, 5000 Namur, Belgium

" Department of Energy Conversion and Storage, Technical University of Denmark (DTU), Frederiksborgvej 399, PO Box 49, 4000 Roskilde, Denmark

${ }^{n}$ Imec vzw, Division IMOMEC, Universitaire Campus - Wetenschapspark 1, 3590 Diepenbeek, Belgium

${ }^{\square}$ X-LaB, Hasselt University, Universitaire Campus - Agoralaan 1, B-3590 Diepenbeek, Belgium

ABSTRACT: Conjugated polymers and small molecules based on alternating electron donating (D) and electron accepting (A) building blocks have led to state-of-the-art organic solar cell materials governing efficiencies beyond 10\%. Unfortunately, the connection of $\mathrm{D}$ and $\mathrm{A}$ building blocks via cross-coupling reactions does not always proceed as planned, which can result in the generation of side products containing D-D or A-A homocoupling motifs. Previous studies have reported a reduced performance in polymer and small molecule solar cells when such defect structures are present. A general consensus on the impact of homocouplings on device performance is, however, still lacking, as well as a profound understanding of the underlying causes of the device deterioration. To differentiate the combined effect of molecular weight and homocouplings in polymer solar cells, a systematic study on a small molecule system $\left(\mathrm{DTS}\left(\mathrm{FBBTh}_{2}\right)_{2}\right)$ is presented here. The impact of homocouplings on the blend nanomorphology, thermal, and electrooptical properties is investigated. It is demonstrated that small quantities of homocouplings $(<10 \%)$ already lead to sub-optimal device performance, as this strongly impacts the molecular packing and electronic properties of the photoactive layer. These results highlight the importance of material purity and pinpoint homocoupling defects as one of the most probable reasons for batch-to-batch variations.

\section{INTRODUCTION}

Semiconducting polymers and analogous small molecules offer vast potential toward organic electronic applications such as photodetectors, transistors, and light-emitting diodes. ${ }^{1-4}$ Furthermore, their tunable material properties render them excellent candidates for solar cell applications. The wide research in- terest in organic photovoltaics (OPV's) has led to record efficiencies up to an impressive $12 \%$ for single junction cells. ${ }^{5,6}$ However, these top results have been achieved with small labscale devices. Since the applied device preparation methodology (i.e. usually spin-coating) is not compatible with the production of large area solar cells, a translation to printing techniques such as spray coating and roll-to-roll coating has to be made. For this purpose, material availability on a reasonable 
scale (i.e. multi-gram to kilogram), in high quality and with reproducible properties, is of crucial importance and yet to be achieved in the field. Although during recent years the access to state-of-the-art materials has significantly improved due to the start-up of some small and medium sized companies, it often remains difficult to reproduce results, which has been attributed to batch-to-batch variations in quality of the active material, especially for semiconducting polymers. Besides the effects of varying end groups,,${ }^{7,8}$ branching,,${ }^{9}$ and the impact of trace impurities of residual metal catalysts, ${ }^{10}$ it has been shown that the molecular weight of semiconducting polymers and its distribution have a strong effect on the electro-optical performances of the corresponding electronic devices. Several studies have revealed that removal of low molar mass components in push-pull polymers is crucial toward optimization of device performance and stability. ${ }^{11-14}$

The state-of-the-art OPV materials are composed of alternating electron donating (D) and electron accepting (A) moieties (the "push-pull" design), aiming to reduce the band gap, hereby increasing photon collection. This strategy has the additional advantage that the highest occupied molecular orbital (HOMO) and lowest unoccupied molecular orbital (LUMO) energy levels can be tuned rather independently. These low band gap polymers are typically prepared via palladium catalyzed cross-coupling polycondensation reactions (mostly Stille ${ }^{15}$ ) between an aryl halide and an organometallic monomer. Ideally, this synthesis procedure yields perfectly alternating copolymers, since the carbon-halide bond can only react with an organometallic bond and vice versa.

However, the alternation of D and A units does not always proceed as intended, as we recently demonstrated for a series of commercial PTB-7 ((poly\{[4,8-bis(2'-ethylhexyloxy)benzo[1,2- $\left.b: 4,5-b^{\prime}\right]$ dithiophene-2,6-diyl]-alt-(3-fluoro2-[(2'-ethylhexyloxy)carbonyl] thieno[3,4-b]thiophene-4,6diyl)\}) batches. ${ }^{16}$ The presence of homocoupled products was observed within the low molar mass parts of the (bimodal) polymer distributions, supporting the report by Yu et al. that homocouplings can occur and affect the photovoltaic efficiency. ${ }^{16,17}$ The detrimental effect of homocouplings on photovoltaic performance has also been observed for other polymer systems. ${ }^{18-}$ ${ }^{23}$ Table S1 (see Supporting Information (SI)) provides an overview of the few previous studies which link photovoltaic performance to the possible presence of homocouplings within the polymer chain distribution. The data clearly illustrate the difficulty in disentangling the influence of homocouplings from molecular weight effects in polymer solar cells. It has to be emphasized that for polymers it is not straightforward to reveal and quantify the presence of homocouplings. These issues limit the suitability of polymers to systematically study the effect of homocouplings on the opto-electronic properties and device characteristics, especially since this side reaction can occur unexpectedly. Previous work by Janssen et al. and Yu et al. has shown that homocoupling can even occur under optimized reaction conditions, forming up to $10 \%$ of the undesirable side products. ${ }^{17,18}$ In this context, small molecules can be very interesting probes since they have a defined molecular structure and, more importantly, they allow for a straightforward structural characterization via NMR spectroscopy and mass spectrometry. The push-pull design strategy has led to a drastic decrease of the HOMO-LUMO gap of small molecules, also resulting in top OPV efficiencies exceeding 10\%. ${ }^{6,24-26}$ Therefore, these compounds are often presented as viable alternatives for polymer donor materials in organic solar cells, with the benefits of reduced batch-to-batch variation, straightforward chemistry and purification. Recent studies on different series of D-A solution processed small molecules revealed also for these materials the importance of homocoupled side products and their pronounced effect on photovoltaic performance. ${ }^{27,28}$ Removal of the homocoupled products is, however, not as straightforward as often thought or claimed, and several purification steps might be needed to eradicate the unwanted structures.

To eliminate the molecular weight issue and to identify the true origin of their influence on device performance, a systematic study of homocouplings in a solution processable small molecule system is presented in this work. By combining morphological characterization, thermal analysis, and advanced electro-optical techniques, we demonstrate the pronounced effect of homocouplings on the blend nanomorphology. To examine the electronic structure of DTS $\left(\mathrm{FBTTh}_{2}\right)_{2}$ and DTS $\left(\mathrm{FBTTh}_{2}\right)_{2}$-homo, density functional theory (DFT) calculations were performed. The molecular packing and electronic properties of the photoactive layer are strongly altered upon addition of homocoupled compounds, leading to a serious deterioration of device efficiency. These results clearly demonstrate the importance of material purity to reduce batch-to-batch variations.
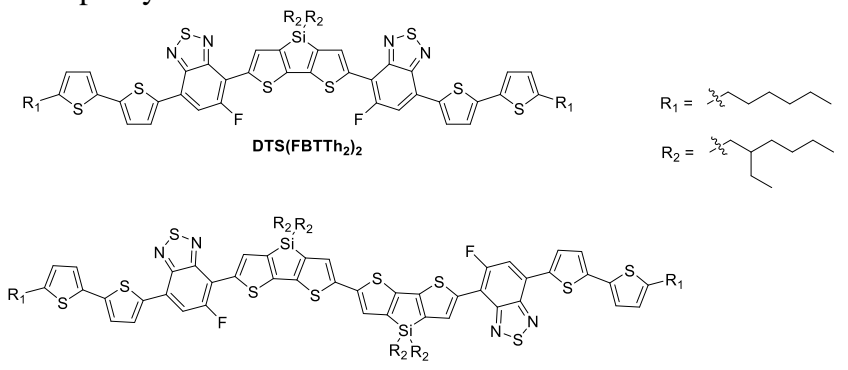

DTS $\left(\text { FBTTh }{ }_{2}\right)_{2}$-homo

Figure 1. Chemical structures of DTS(FBTTh2 $)_{2}$ and DTS(FBTTh2)2-homo.

Table 1. Overview of the different mixing ratios of

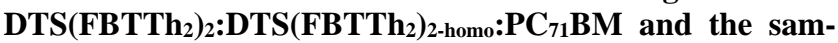
ple nomenclature used throughout this study.

\begin{tabular}{lll}
$\begin{array}{l}\text { Sample } \\
\text { name }\end{array}$ & $\begin{array}{l}\text { DTS }\left(\mathrm{FBTTh}_{2}\right)_{2}: \\
\mathrm{DTS}\left(\mathrm{FBTTh}_{2}\right)_{2 \text {-homo: }} \mathrm{PC}_{71} \mathrm{BM} \\
\text { mixing ratio }\end{array}$ & $\begin{array}{l}\text { Fraction of homo- } \\
\text { coupled product } \\
\chi^{\text {homo }}(\%)\end{array}$ \\
\hline$\chi_{0}^{\text {homo }}$ & $60: 0: 40$ & 0 \\
$\chi_{10}^{\text {homo }}$ & $54: 6: 40$ & 10 \\
$\chi_{20}^{\text {homo }}$ & $48: 12: 40$ & 20 \\
$\chi_{50}^{\text {homo }}$ & $30: 30: 40$ & 50 \\
$\chi_{100}^{\text {homo }}$ & $0: 60: 40$ & 100 \\
\hline
\end{tabular}

\section{RESULTS AND DISCUSSION}

\subsection{Synthesis and characterization}

To perform an in-depth study on the impact of homocoupling on the physicochemical material properties of molecular chromophores and the corresponding device features, the small molecule DTS(FBTTh $)_{2}$ was selected, as it is a high-performing OPV material which has already been studied thoroughly in literature. If homocoupling would occur during the last (Stille cross-coupling) synthesis step, a small molecule with two adjacent central DTS (4H-dithieno[3,2-b:2',3'-d] silole) units would 
be generated. To allow a systematic study, this homocoupled small molecule (DTS(FBTTh $\left.{ }_{2}\right)_{2 \text {-homo, }}$ Figure 1) was synthesized and mixed with DTS(FBTTh $)_{2}$ in known quantities (see Table 1 for the mixing ratios and the denotation of the different samples). The synthesis protocol toward DTS(FBTTh $\left.{ }_{2}\right)_{2 \text {-homo }}$ is included in the SI. DTS(FBTTh $\left.{ }_{2}\right)_{2}$ was acquired from 1-Material. The purity of both materials was verified by NMR spectroscopy and mass spectrometry (see SI). The MALDI-TOF mass spectrum of the commercial DTS(FBTTh $\left.)_{2}\right)_{2}$ sample reveals the presence of a small amount of DTS(FBTTh $\left.{ }_{2}\right)_{2}$-homo (Figure S5.1). However, from the analysis of the $\chi_{10}^{\text {homo }}$ sample (without $\left.\mathrm{PC}_{71} \mathrm{BM}\right)$, it is clear that MALDI-TOF is particularly sensitive to the presence of DTS(FBTTh $\left.{ }_{2}\right)_{2 \text {-homo }}$ and this technique does not allow quantification of the amount of impurities. Therefore, detailed ${ }^{1} \mathrm{H}$ NMR analysis was performed. It is shown that the signals arising from DTS(FBTTh $\left.)_{2}\right)_{2 \text {-homo }}$ are substantially smaller than the ${ }^{13} \mathrm{C}$ satellite signals of DTS $\left(\mathrm{FBTTh}_{2}\right)_{2}$ (see SI). Therefore, it can be concluded that only trace amounts $(<0.5 \%)$ of DTS $\left(\mathrm{FBTTh}_{2}\right)_{2 \text {-homo }}$ are present in this commercial batch of DTS $\left(\mathrm{FBTTh}_{2}\right)_{2}$.

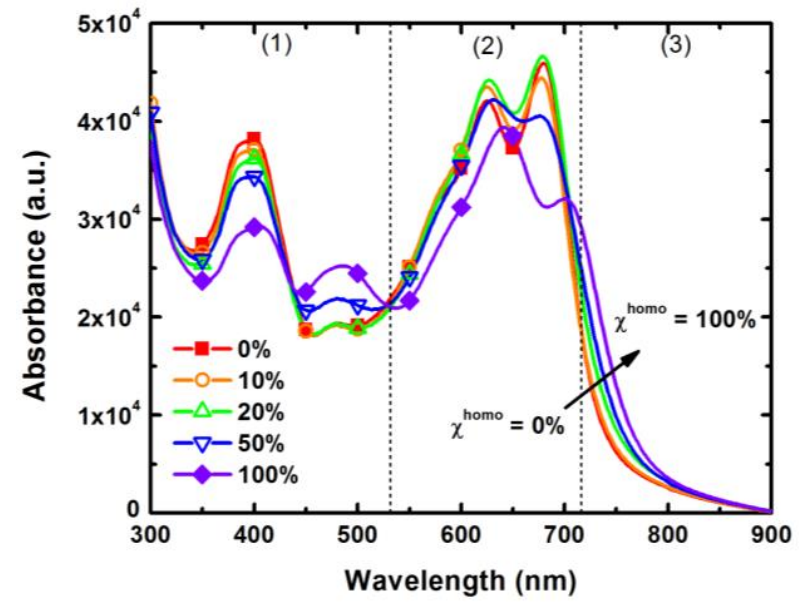

Figure 2. Optical absorption spectra of DTS(FBTTh $)_{2}$ :DTS(FBTTh $)_{2}$-homo:PC ${ }_{71}$ BM blend films for different mixing ratios.

The optical properties of DTS(FBTTh $)_{2}: \mathrm{DTS}\left(\mathrm{FBTTh}_{2}\right)_{2}$ homo: $\mathrm{PC}_{71} \mathrm{BM}$ blend films with different mixing ratios were investigated by ultraviolet-visible (UV-Vis) absorption spectroscopy (Figure 2). The absorbance has been corrected for the layer thickness of the samples. Several features can be distinguished when changing the homocoupled fraction $\left(\chi^{\text {homo }}\right)$ from 0 to $100 \%$ : (1) the ratio of the absorption peaks at $400 \mathrm{~nm}$ and 480 $\mathrm{nm}$ decreases upon increasing the homocoupling concentration, (2) the ratio of the two vibronic peaks between 600 and $700 \mathrm{~nm}$ changes significantly for $\chi^{\text {homo }}>20 \%$, and the peak positions red-shift for $\chi_{100}^{\text {homo }}$, (3) the absorption tail red-shifts with increasing $\chi^{\text {homo }}$, although the difference between $\chi_{0}^{\text {homo }}$ and $\chi_{10}^{\text {homo }}$ is barely visible. The $\chi_{20}^{\text {homo }}$ sample shows a slightly more pronounced red shift, but the other features do not vary much as compared to $\chi_{0}^{\text {homo }}$. These results indicate that the presence of low homocoupling concentrations $\left(\chi^{\text {homo }} \leq 20 \%\right)$ does not significantly influence the overall optical properties. The change in the vibronic peak ratio between 600 and $700 \mathrm{~nm}$ could be an indication that the film morphology differs, as these peaks can be related to ordered regions within the active layer. However, these are not significantly changing when $\chi^{\text {homo }} \leq 20 \%$. This is confirmed by photoluminescence (PL) measurements of DTS(FBTTh $)_{2}:$ DTS(FBTTh $\left.{ }_{2}\right)_{2 \text {-homo }}:$ PC $_{71}$ BM blend films on glass (Figure $\mathrm{S} 13$ ), where a clear red-shift is observed with increasing amount of homocoupled species. The PL spectra do not reveal any significant difference in PL quenching between the various samples, especially for $\chi^{\text {homo }} \leq 20 \%$.

\subsection{Photovoltaic performance}

The photovoltaic parameters as a function of the mixing ratio of DTS $\left(\text { FBTTh }_{2}\right)_{2}$ and DTS(FBTTh $)_{2}$-homo are shown in Table 2. The values are averaged over $12-16$ devices. The layer thickness for all devices was optimized using the best performing solvent system for DTS $\left(\mathrm{FBTTh}_{2}\right)_{2}$ as found in literature. ${ }^{29}$ The $J-V$ curves can be found in the SI, as well as an overview of the photovoltaic parameters as a function of $\chi^{\text {homo }}$. The efficiency obtained for DTS(FBTTh $)_{2}: \mathrm{PC}_{71} \mathrm{BM}$ is similar to reported literature values. ${ }^{29}$ Addition of the homocoupled compound leads to a reduction of the short-circuit current density $\left(J_{\mathrm{SC}}\right)$, fill factor $(\mathrm{FF})$ and open-circuit voltage $\left(V_{\mathrm{OC}}\right)$, which results in an overall lowering of the power conversion efficiency (PCE). The PCE already drops significantly for $\chi_{10}^{\text {homo }}$, clearly demonstrating suboptimal performance. The lowest value is reached for $\chi_{20}^{\text {homo }}$ (suggesting a minimum around that composition), where the efficiency is half of the value for $\chi_{0}^{\text {homo }}$. It is clear that, in contrast to the optical properties, the photovoltaic performance is already strongly influenced by the presence of low homocoupling concentrations. The sample $\chi_{5}^{\text {homo }}$ was solely added to verify the observed trend in decreasing solar cell performance. In the remainder of this study, the origin of the reduced performance is studied by comparing $\chi_{0}^{\text {homo }}, \chi_{10}^{\text {homo }}, \chi_{20}^{\text {homo }}, \chi_{50}^{\text {homo }}$ and $\chi_{100}^{\text {homo }}$.

Table 2. Photovoltaic parameters for different concentrations of the homocoupled product. Averages are taken over 12-16 devices. The errors represent the standard deviations. The graphical representation can be found in Figure S6.1.

\begin{tabular}{cccccc}
\hline $\begin{array}{c}\text { Sample } \\
\text { name }\end{array}$ & $\begin{array}{c}V_{\mathrm{OC}} \\
(\mathrm{mV})\end{array}$ & $\begin{array}{c}J_{\mathrm{SC}} \\
\left(\mathrm{mA} \mathrm{cm}^{-2}\right)\end{array}$ & $\begin{array}{c}J_{\mathrm{SC}, \mathrm{EQE}} \\
\left(\mathrm{mA} \mathrm{cm}^{-2}\right)\end{array}$ & $\begin{array}{c}\mathrm{FF} \\
(\%)\end{array}$ & $\begin{array}{c}\mathrm{PCE} \\
(\%)\end{array}$ \\
\hline$\chi_{0}^{\text {homo }}$ & $774 \pm 7$ & $13.1 \pm 0.4$ & 12.50 & $67.5 \pm 1.0$ & $6.8 \pm 0.2$ \\
$\chi_{5}^{\text {homo }}$ & $758 \pm 4$ & $11.5 \pm 0.5$ & $/$ & $64.7 \pm 2.0$ & $5.6 \pm 0.2$ \\
$\chi_{10}^{\text {homo }}$ & $726 \pm 6$ & $10.9 \pm 0.5$ & 10.80 & $62.9 \pm 1.7$ & $5.0 \pm 0.3$ \\
$\chi_{20}^{\text {homo }}$ & $689 \pm 4$ & $8.5 \pm 0.5$ & 8.08 & $59.7 \pm 2.0$ & $3.5 \pm 0.3$ \\
$\chi_{50}^{\text {homo }}$ & $664 \pm 8$ & $9.4 \pm 0.6$ & 8.33 & $63.8 \pm 1.9$ & $4.0 \pm 0.3$ \\
$\chi_{100}^{\text {homo }}$ & $640 \pm 5$ & $11.3 \pm 0.5$ & 10.53 & $61.0 \pm 1.4$ & $4.5 \pm 0.2$ \\
\hline
\end{tabular}

\subsection{Origin of the reduced $J_{\mathrm{SC}}$ and FF}

\subsubsection{Relation to morphology}

The photocurrent and FF depend strongly on the morphological composition of the photoactive layer in bulk heterojunction solar cells. It is known that the morphology of binary bulk heterojunctions can comprise multiple phases. A 'three-phase' morphology is often mentioned as the preferred condition to achieve optimal performance. ${ }^{30-32}$ These three phases consist out of pure aggregated (i) donor and (ii) fullerene domains, and (iii) mixed amorphous regions of the donor material with fullerene. The aggregated regions of the pure materials assist the extraction of charges generated in the mixed regions. It has been suggested by several studies that a high degree of intermixing of fullerene and polymer or small molecule results in a higher charge generation. ${ }^{33-35}$

Recently, Ade et al. demonstrated a direct quantitative relationship between FF, $J_{\mathrm{SC}}$, and the morphological composition of 
DTS(FBTTh $)_{2}:$ PC $_{71}$ BM blend films. ${ }^{36}$ The outcome of their study was that relatively small domains, consisting of amorphous intermixed domains and pure aggregate phases (of
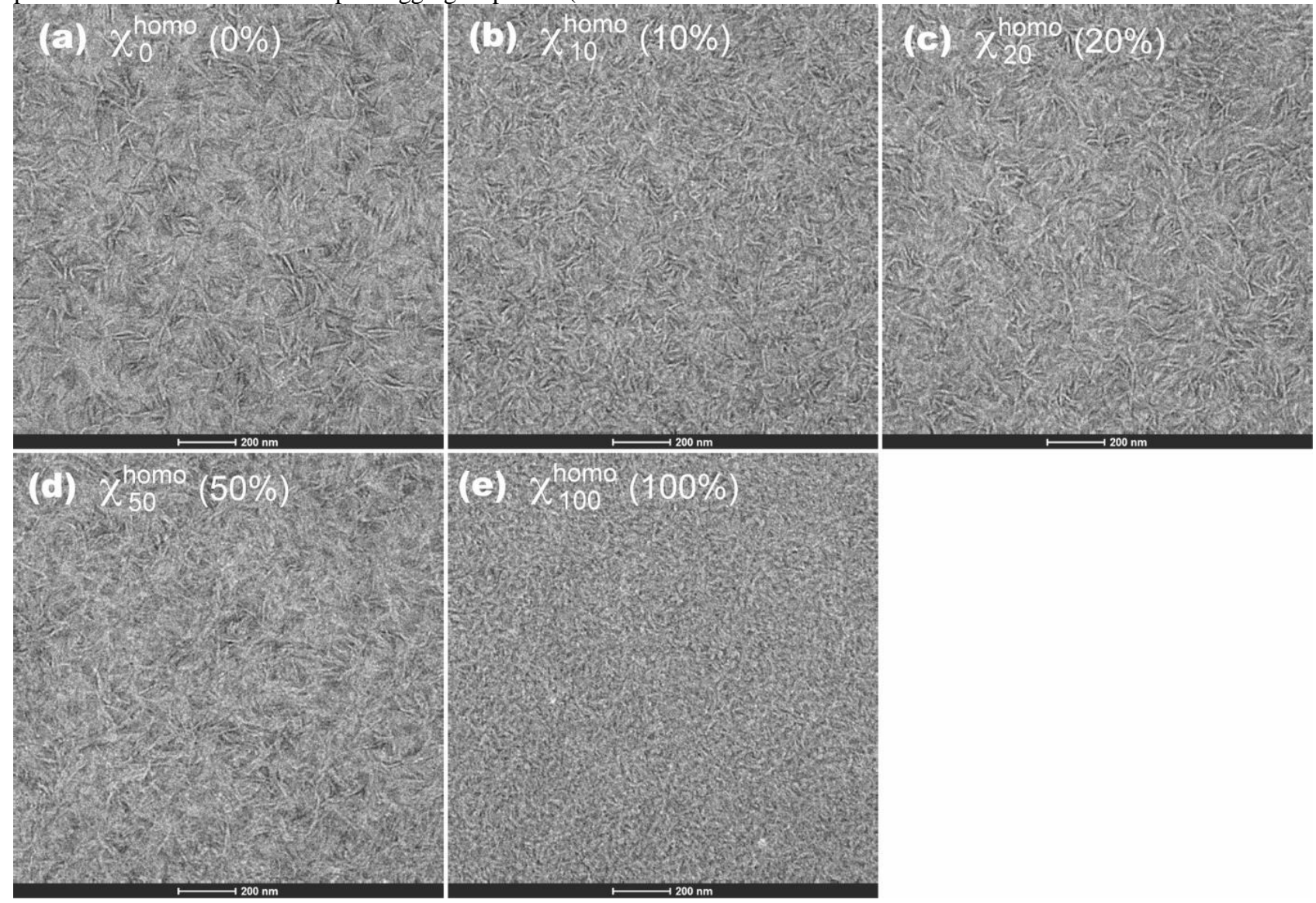

Figure 3. Transmission electron microscopy images for $\chi^{\text {homo }}$ blend films. All images were recorded in bright field with an underfocus of $20 \mu \mathrm{m}$ and magnification of $30 \mathrm{kx}$. The scalebar always represents $200 \mathrm{~nm}$.

DTS(FBTTh $\left.{ }_{2}\right)_{2}$ and $\left.\mathrm{PC}_{71} \mathrm{BM}\right)$, are essential to obtain optimal device performance. In this system, a small modification in the morphological composition can thus already strongly affect the device performance.

When homocouplings are present, the binary system becomes an unintended ternary system, which may be comprised out of multiple phases, such as pure aggregated regions of

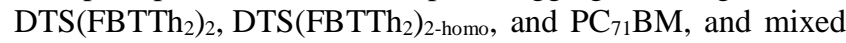
amorphous regions of both molecules with $\mathrm{PC}_{71} \mathrm{BM}$. Furthermore, the two molecules might also be interacting in a specific ratio with each other.

For this reason, morphological examination of the ternary system is done via transmission electron microscopy (TEM), grazing incidence wide angle X-ray scattering (GIWAXS), and rapid heat calorimetry (RHC). The TEM images are shown in Figure 3. Fibrillar structures are visible for the blend $\chi_{0}^{\text {homo }}$, similar to literature. ${ }^{37}$ Upon the addition of DTS $\left(\text { FBTTh }_{2}\right)_{2 \text {-homo }}$ to the blend ( $\chi_{10}^{\text {homo }}$ and $\left.\chi_{20}^{\text {homo }}\right)$, the fiber width and length become smaller and their density alters. Further increase in $\chi^{\text {homo }}\left(\chi_{50}^{\text {homo }}\right)$ decreases the fiber size even more, eventually resulting in a morphology with a much finer scale for $\chi_{100}^{\text {homo }}$.

The morphological differences for the studied samples with DTS(FBTTh $)_{2}$-homo addition ranging from 0 to $20 \%$ are rather subtle. Therefore, GIWAXS was used to gain a better understanding of the molecular packing and film morphology (see SI for GIWAXS set-up). The 2D GIWAXS patterns of the
DTS(FBTTh $)_{2}$ :DTS(FBTTh $)_{2}$ 2-homo:PC $_{71}$ BM blends, measured at room temperature, can be found in Figure 4 . The data clearly demonstrate that the presence of homocouplings strongly modifies the molecular packing motifs, driving the molecules to qualitatively different morphologies. Owing to the GIWAXS scattering geometry, the resolution is restricted, and it is thus not possible to estimate the crystallite size based on these data. Similarly, the absolute degree of crystallinity is difficult to extract from GIWAXS data. The prowess of GIWAXS is to provide insights into crystal structures and texture with respect to the substrate. ${ }^{38-40}$

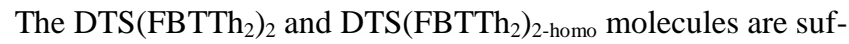
ficiently bulky and disordered for the scattering patterns to resemble those found for many conjugated polymers. It is thus tempting to refer to the three low- $Q$ reflections as arising from a rather well-defined lamellar stacking, which in conjugated polymers corresponds to the molecular spacing warranted by e.g. alkyl side chains. For a homocoupling concentration of 0 and $10 \%$, the scattering patterns exhibit a lamellar stacking with a well-defined texture near the $Q_{z}$ (meridian) axis, having $Q_{z}=$ $h \times 0.27 \AA^{-1}(h \in 1 . .3)$, which can be accounted for by a real space repetition distance of $23 \AA$. This suggests that the molecules are oriented with their long axis parallel to the substrate and the side chains oriented parallel to the substrate normal, as often observed for alkyl-substituted conjugated polymers. ${ }^{38,41}$ 
For $\chi_{20}^{\text {homo }}$, the peak is shifted to $Q=0.29 \AA^{-1}$ and becomes increasingly pronounced when further increasing the homocoupling contribution to $100 \%$. We note that the peak actually splits at $\chi_{100}^{\text {homo }}$, suggesting the presence of multiple competing arrangements. There are also Debye-Scherrer rings centered at about $Q$ $\sim 1.3 \AA^{-1}(d=4.8 \AA)$ and $Q \sim 1.7 \AA^{-1}(d=3.7 \AA)$. The former ring has previously been assigned to amorphous fullerene, and indeed, it is seen in the measurement series that this ring is essentially isotropic. ${ }^{42}$

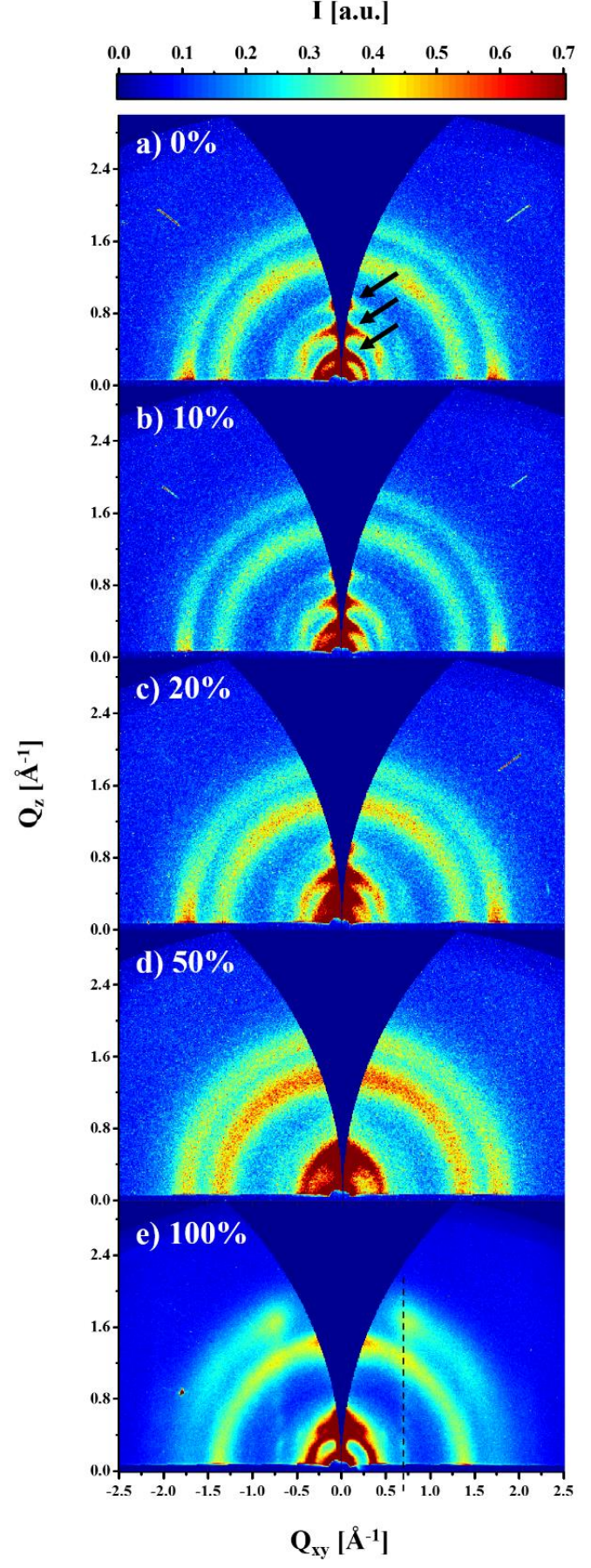

Figure 4. Two-dimensional GIWAXS patterns for DTS(FBTTh2 $)_{2}$ :DTS(FBTTh2)2-homo:PC ${ }_{11} \mathrm{BM}$ blends with increasing concentration of homocoupling. The patterns have been interpolated to rectilinear and orthogonal $\left(Q_{\mathrm{xy}}, Q_{\mathrm{z}}\right)$ coordinates to correct for the curvature of the Ewald sphere. This procedure reveals the missing wedge of data near the $Q_{\mathrm{z}}$ axis. The black arrows in a) indicate the well-defined scattering along an axis near $Q_{z}$. The dotted line at $Q_{\mathrm{xy}} \sim 0.7 \AA^{-1}$ in e) highlights the vertical Bragg-rod feature of increased scattering intensity, tentatively attributed to lateral sliding of loosely ordered molecular stacks.

Interestingly, it appears that the intensity of the $\mathrm{PC}_{71} \mathrm{BM}$ ring increases with the homocoupling density, suggesting that the more disordered DTS(FBTTh $\left.{ }_{2}\right)_{2}$ :DTS(FBTTh $\left.{ }_{2}\right)_{2}$-homo blends induce increased disorder also in the $\mathrm{PC}_{71} \mathrm{BM}$. The other ring $(Q$ $\sim 1.7 \AA^{-1}$ ) is in the range usually observed for $\pi$-stacking, and indeed, the fact that the reflection has its maximum near the $Q_{\mathrm{xy}^{-}}$ plane is consistent with the presence of in-plane $\pi$ - $\pi$ stacking. A noteworthy observation is the presence of additional features in the scattering patterns, including a vertical streak of increased intensity (diffuse Bragg rod) seen at $Q_{\mathrm{xy}} \sim 0.7 \AA^{-1}(d=9 \AA)$ for $\chi^{\text {homo }}=100 \%$. The origin of this feature might be lateral sliding of complete loosely ordered molecular stacks with respect to each other, in other words lamella having lost their lateral registry with respect to each other. ${ }^{43}$ The fact that the Bragg peaks on the $Q_{\mathrm{z}}$ axis remain sharp is consistent with this structural model of smectic layers. The TEM and GIWAXS measurements in our study clearly demonstrate that the morphology and molecular packing are significantly altered upon the presence of homocouplings.

As it was not possible to quantify the crystalline regions via GIWAXS, thermal analysis by rapid heat-cool calorimetry (RHC) was performed on the $\chi_{0}^{\text {homo }}$ and $\chi_{20}^{\text {homo }}$ blends. In Figure $\mathrm{S} 12 \mathrm{a}$, the first heating at $500 \mathrm{~K} \mathrm{~min}^{-1}$ (dashed line) shows the effect of the preceding solution processing using 1,8-diiodooctane (DIO). Then, slow cooling at $1 \mathrm{~K} \mathrm{~min}^{-1}$ was applied to allow thermal structure formation in quasi equilibrium conditions, followed by a second heating at high rate $\left(500 \mathrm{~K} \mathrm{~min}^{-1}\right.$; solid line) to preserve the effects of the preceding slow cooling and minimize cold crystallization and crystal reorganization during heating. The high heating rate also increases the sensitivity to detect the glass transition and melting peak. Both samples show a rather narrow melting peak below $200{ }^{\circ} \mathrm{C}$ in the second heating. The melting enthalpy of $20.5 \mathrm{~J} \mathrm{~g}^{-1}$ for $\chi_{0}^{\text {homo }}$ is lowered to $13 \mathrm{~J} \mathrm{~g}^{-1}$ for $\chi_{20}^{\text {homo }}$, after subtraction of the contribution of cold crystallization, indicating a clearly reduced crystallinity by addition of $20 \%$ of DTS(FBTTh $)_{2}$-homo for the same conditions of solution processing and thermal analysis. The presence of $20 \%$ homocoupled material lowers the crystallization rate of $\chi_{20}^{\text {homo }}$ against $\chi_{0}^{\text {homo }}$, which is most obvious in the first heating curves; the melting enthalpy of $\chi_{20}^{\text {homo }}$ is only $2.5 \mathrm{~J} \mathrm{~g}^{-1}$, after subtraction of the significant contribution of cold crystallization, in comparison with $17.5 \mathrm{~J} \mathrm{~g}^{-1}$ for $\chi_{0}^{\text {homo }}$.

Note that for both mixtures no separate melting peak of pure $\mathrm{PC}_{71} \mathrm{BM}$ (around $310^{\circ} \mathrm{C}$ ) is observed. On the other hand, a glass transition for both mixtures is clearly noticed. Its position is largely influenced by DIO, acting as a plasticizer. Residues of DIO are obviously present, although this solution processing aid, tuning the evaporation rate of the solvent and by this the initially developed nanomorphology, was removed in vacuo. As an illustration, Figure S12b shows the RHC thermogram of $\chi_{0}^{\text {homo }}$ processed without DIO. In this case, a glass transition around $130{ }^{\circ} \mathrm{C}$ and an even sharper melting peak with a melting enthalpy of $23 \mathrm{~J} \mathrm{~g}^{-1}$ is noticed. It should be emphasized that a clear glass transition can only be observed in the presence of $\mathrm{PC}_{71} \mathrm{BM}(40 \%)$. This amorphous phase should have a mixed composition, with contributions of all components, i.e. DTS $\left(\text { FBTTh }_{2}\right)_{2}$, DTS $\left(\text { FBTTh }_{2}\right)_{2}$-homo and PC $_{71}$ BM (the glass transition of pure $\mathrm{PC}_{71} \mathrm{BM}$ is around $\left.166^{\circ} \mathrm{C}\right)$. 
The TEM, GIWAXS and RHC measurements demonstrate that the morphology and molecular packing are significantly altered upon the presence of homocouplings. It seems that the presence of homocoupled molecules inherently drives the morphology away from the optimal composition, which is extremely critical for $J_{\mathrm{SC}}$ and $\mathrm{FF}$, as already illustrated by Ade et al. for the DTS $\left(\text { FBTTh }_{2}\right)_{2}$ model system. ${ }^{36}$ The molecular arrangement of the fullerene is also modified. All these arguments suggest that changes in the nanomorphology are the main driver for the differences in photocurrent and FF.

Besides the inherent de-optimization upon the presence of homocouplings, we also would like to note that there is a slight alteration in the side chain pattern of DTS $\left(\mathrm{FBTTh}_{2}\right)_{2}$-homo, which influences the solubility and the eventual morphology. Studies on polymers and small molecules have shown a direct correlation between the side chains, solubility and morphology. ${ }^{44,45}$

\subsubsection{Relation to absorption}

Besides the morphological features, the photocurrent depends strongly on the absorption characteristics and charge transport (which also depends on the nanomorphology). External quantum efficiency (EQE) spectra of the photovoltaic devices (Table 2) are shown in Figure 5a. The EQE expresses the ratio of extracted charges to incoming photons at each wavelength. Integration of the EQE over the AM1.5G spectrum yields $J_{\mathrm{SC}, \mathrm{EQE}}$ values with a similar trend to those obtained by $J$ - $V$ characterization with the solar simulator. Compared to the absorption spectra, the two peaks located at 630 and $670 \mathrm{~nm}$ appear to flatten out and red shift, similar to the shift observed in the absorption spectra (Figure 2). The trend in EQE (and thus $J_{\mathrm{SC}}$ ) could be due to differences in photon absorption. Therefore, the absorption coefficient $\alpha$ was determined via absolute absorption measurements (Figure 5b). The blend films were deposited on glass substrates using the same processing conditions as for the optimized devices. From the obtained spectra, it is possible to estimate the flux of absorbed photons by integrating the product of the fraction of absorbed photons and the AM1.5G solar spectrum with respect to the photon energies. The fraction of absorbed photons is calculated from $\alpha$ by taking the optimal layer thickness of the active layer and reflection of the back electrode into consideration, but neglecting any interference effects. ${ }^{46} \mathrm{By}$ multiplying the absorbed photon flux by the electron charge, an estimate for the maximum attainable current $\left(J_{\mathrm{SC}}\right.$, abs. photons $)$ is obtained. This method is solely used to perform a qualitative analysis, as the transmission/reflection measurements were not performed on full device stacks. Figure 5c displays the measured and calculated $J_{\mathrm{SC}}$ values as a function of $\chi^{\text {homo }}$. It becomes clear that the absorption of photons is not responsible for the observed relationship of $J_{\mathrm{SC}}$, as $J_{\mathrm{SC} \text {, abs. photons }}$ and $J_{\mathrm{SC}}$ follow a different trend. This suggests that the charge transport and extraction are hindered upon the incorporation of homocoupled molecules.

This is also confirmed by photo-induced charge extraction by linearly increasing voltage (pCELIV) measurements (vide infra), which reveal a slight reduction of the charge carrier mobility for the ternary blends (Figure 6c).

\subsection{Origin of the reduced $V_{O C}$}

Recent studies on polymer solar cells indicate that the presence of homocouplings often leads to a drop in $V_{\text {OC. }}{ }^{18-23}$ Although this is a rather small drop in the case of polymer solar cells, it could be a useful fingerprint to track the presence of electron rich homocoupled molecules when comparing solar cells with the same device architecture. For small molecules, the difference in $V_{\mathrm{OC}}$ can be larger (up to $170 \mathrm{mV}$ ). ${ }^{28}$ Instead of having a binary bulk heterojunction, the presence of homocouplings can be regarded as the formation of an unintended (and unwanted) ternary system.
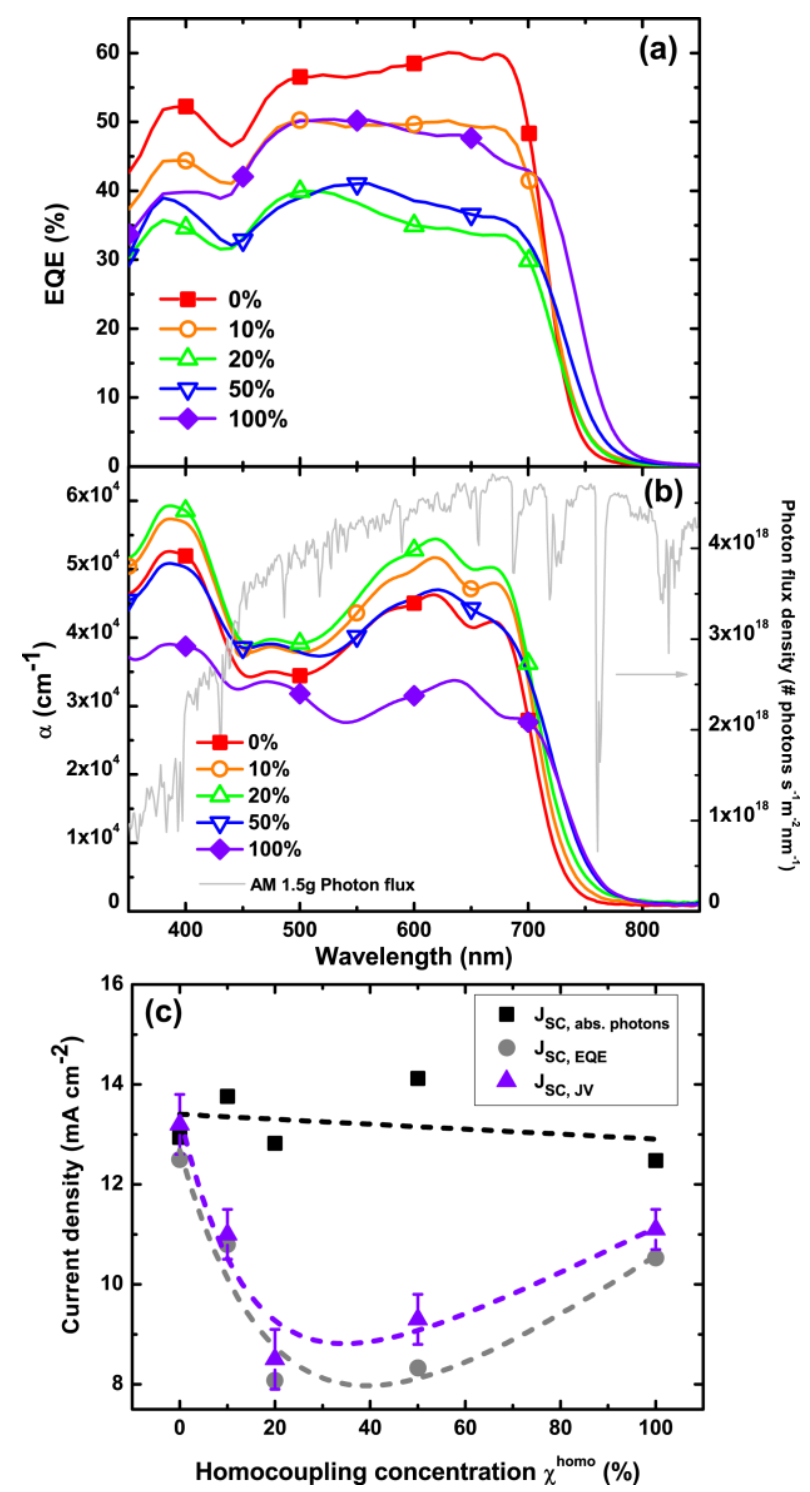

Figure 5. (a) External quantum efficiency for different homocoupling concentrations ( $\left.\chi^{\text {homo }}\right)$. (b) Absorption coefficient $\alpha$ for different $\chi^{\text {homo }}$ and the AM1.5G photon flux (grey line). (c) Short-circuit current density $\left(J_{\mathrm{SC}}\right)$ obtained via calculation from $\mathrm{EQE}$ ( $\left.J_{\mathrm{SC}, \mathrm{EQE}}\right)$, absolute absorption $\left(J_{\mathrm{SC} \text {,abs. photons }}\right)$, and $J-V$ measurements $\left(J_{\mathrm{SC}}, \mathrm{JV}\right)$ as a function of $\chi^{\text {homo }}$. The dashed lines serve as guides to the eye only.

Furthermore, it has recently been shown that multiple homocoupled products can reside within a batch distribution, ${ }^{16,28}$ which implies that a system can become very complicated to study (as it could be quaternary, quintary, etc. depending on the 
number of side products). The ability to tune the $V_{\mathrm{OC}}$ is often considered as an advantage to increase device performance in ternary blends and has been studied by several research groups. ${ }^{47-51}$ According to literature, two pathways are responsible for the tunability: compositional effects, e.g. the formation of a specific composition, and/or morphological effects, e.g. aggregated or amorphous regions. By probing the charge transfer (CT) state, it becomes possible to study such kind of effects and relate them to $V_{\mathrm{OC}}$.
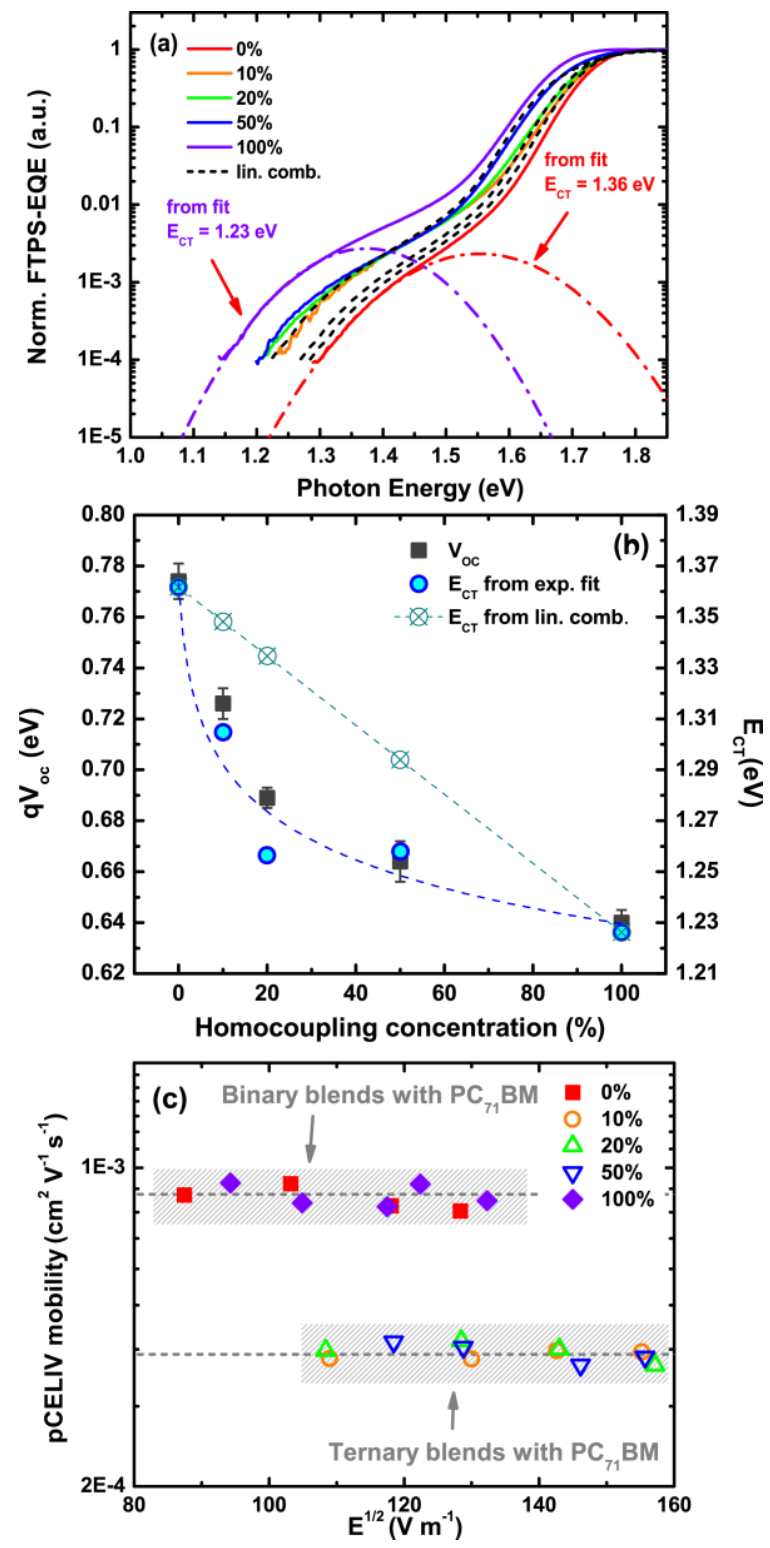

Figure 6. (a) FTPS-EQE spectra normalized to absolute EQE spectra for the different blends. The black dashed lines correspond to linear combinations of the DTS(FBTTh 2$)_{2}$ and DTS(FBTTh2 $)_{2}$-homo FTPS-EQE spectra, which fail to reproduce the measured spectra. (b) $q V_{\mathrm{OC}}$ and $E_{\mathrm{CT}}$ as a function of the concentration of added homocoupled product. Both y-axes show the same energy interval. The green and blue dashed lines serve as guides to the eye only. (c) Photo-CELIV mobility as a function of the electric field with varying degree of homocoupling. The binary $\left(\chi^{\text {homo }}=0\right.$ and $\left.100 \%\right)$ and ternary $\left(\chi^{\text {homo }}=10,20\right.$, and $\left.50 \%\right)$ blends show a significant difference in mobility.

It has been shown on numerous occasions that mixing of semiconducting organic molecules (e.g. polymer and fullerene) leads to a new intermediate state, which is defined as the charge transfer or CT state, with a distinctive energy $\left(E_{\mathrm{CT}}\right) .^{52}$ The CT state can be probed by sensitive photocurrent measurements such as Fourier transform photocurrent spectroscopy (FTPS) or sensitive external quantum efficiency (sEQE) measurements. Vandewal et al. revealed a linear relationship between $E_{\mathrm{CT}}$ and $V_{\text {OC. }}$ Furthermore, they showed that $E_{\mathrm{CT}}$ is strongly related to the energy gap between the HOMO of the donor and the LUMO of the acceptor. ${ }^{53}$ It is generally accepted that a deeper lying HOMO level of the donor material gives rise to a higher $V_{\mathrm{OC}}{ }^{54}$ The FTPS-EQE spectra (colored lines) shown in Figure 6a were scaled to the absolute EQE measurements and merged together. $E_{\mathrm{CT}}$ was determined via fitting of the CT absorption according to Marcus theory. ${ }^{52}$ For clarity, only the fits of $\chi_{0}^{\text {homo }}$ and $\chi_{100}^{\text {homo }}$ are shown (the complete fitting summary can be found in the SI). The evolution of $q V_{\mathrm{OC}}$ ( $q$ is the elementary charge) upon changing $\chi^{\text {homo }}$ is plotted in Figure $6 b$, together with the extracted $E_{\text {Ст. }}$ The intervals of both y-axes are set identical. The trend in $q V_{\mathrm{OC}}$ and $E_{\mathrm{CT}}$ is very similar, implying that the change in $V_{\mathrm{OC}}$ can be attributed to changes in the CT state energetics. The energetic difference between the highest and the lowest $q V_{\mathrm{OC}}$ (and $E_{\mathrm{CT}}$ ) equals to roughly $130 \mathrm{meV}$. These differences can be caused by morphological changes and/or changes in the electronic configuration of the different molecules. ${ }^{51}$ In our case, it is not straightforward to differentiate between these two causes as it could be a combination of both. We already pointed out that there are differences in molecular packing and morphology. By computational analysis (see SI for details), both compounds are found to be planar, except for the terminal thiophene-thiophene torsions, which increase up to $\sim 12^{\circ}$. As expected, the HOMO level of DTS(FBTTh $\left.{ }_{2}\right)_{2}$ is mainly localized on the DTS unit. The addition of a central DTS unit in the homocoupled compound leads to a marked destabilization of the HOMO, resulting in a difference of $170 \mathrm{meV}$ for the HOMO levels between the two molecules. This change in HOMO energy, in good agreement with the measured shift of $130 \mathrm{meV}$, allows rationalizing the observed trend in $E_{\mathrm{CT}}$ and $V_{\mathrm{OC}}$. The LUMO level, which is mainly localized on the benzothiadiazole units, is slightly destabilized in DTS(FBTTh $\left.{ }_{2}\right)_{2 \text {-homo, }}$, resulting in a LUMO difference of $50 \mathrm{meV}$ between the two molecules.

As a consequence of the asymmetric destabilization of the frontier orbitals, the band gap and the onset of the optical absorption are red-shifted in the presence of the homocoupled compound, consistent with the experimental data (Figure 2). The shift in vertical excitation energies attains $0.09 \mathrm{eV}$ (from 1.87 to 1.78 $\mathrm{eV}$ ) and, in addition, for the homocoupled compound a transition occurs at $499 \mathrm{~nm}$ instead of $420 \mathrm{~nm}$. These theoretical data, which are fully consistent with the addition of one electron donating unit in the molecular structure, also nicely follow the trends experimentally observed by cyclic voltammetry (CV) (see SI).

Furthermore, spectral shape analysis of the FTPS-EQE spectra (Figure 6a) can be used to explain the non-linear behavior of $E_{\mathrm{CT}}$ and $V_{\mathrm{OC}}$ as a function of $\chi^{\text {homo }}$. Both molecules, DTS $\left(\mathrm{FBTTh}_{2}\right)_{2}$ and DTS( $\left.\mathrm{FBTTh}_{2}\right)_{2}$-homo, must form a specific CT state environment with $\mathrm{PC}_{71} \mathrm{BM}$. In the past, it has been suggested and illustrated that upon mixing of two polymers with $\mathrm{PC}_{71} \mathrm{BM}$, a parallel-like bulk heterojunction tandem cell can be formed, which can be regarded as two independent binary subcells. ${ }^{47,55}$ If both CT states would exist independently of each other, it should be possible to perform linear combinations of the $\chi_{0}^{\text {homo }}$ and the $\chi_{100}^{\text {homo }}(100 \%)$ CT band spectra, and reconstruct the CT bands of $\chi_{10}^{\text {homo }}, \chi_{20}^{\text {homo }}$, and $\chi_{50}^{\text {homo }}$. The dashed black lines 
in Figure 6a represent linear combinations of blends of

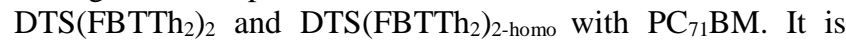
clear that it is not possible to reconstruct any of the CT band spectra with linear combinations, which implies that upon intermixing of DTS $\left(\mathrm{FBTTh}_{2}\right)_{2}$ and DTS $\left(\mathrm{FBTTh}_{2}\right)_{2 \text {-homo, }}$, specific interactions interfere, giving rise to obvious non-linear behavior, as is also the case in mixtures showing an eutectic phase diagram or in mixtures forming new 'compounds' (molecular complexes) at specific compositions. ${ }^{56-58}$ Note that the latter are also called 'alloys' in OPV literature. . $^{5,60}$

This non-linear behavior is supported by pCELIV measurements. pCELIV is a powerful method to gain insight in the mobility of charge carriers within a real device structure. ${ }^{61}$ The mobility of the charge carriers $\left(\mu_{p C E L I V}\right)$ was calculated by using the numerical correction factor used for the moderate mobility case and is plotted as a function of the electric field in Figure 6c. More information on the method, calculation and devices used to obtain the mobility values can be found in the SI. It is possible to divide the samples into two classes: binary blends ( $\chi^{\text {homo }}$ $=0$ and $100 \%)$ and ternary blends $\left(\chi^{\text {homo }}=10,20\right.$, and $\left.50 \%\right)$. For the binary systems, $\mu_{p C E L I V} \approx 8.8 \times 10^{-4} \mathrm{~cm}^{2} \mathrm{~V}^{-1} \mathrm{~s}^{-1}$, while for the ternary systems, $\mu_{p C E L I V} \approx 3.8 \times 10^{-4} \mathrm{~cm}^{2} \mathrm{~V}^{-1} \mathrm{~s}^{-1}$. It is striking that within the same 'class' (binary vs. ternary), the mobility is very similar. We believe this could be related to the formation of additional interactions between DTS $\left(\mathrm{FBTTh}_{2}\right)_{2}$ and DTS(FBTTh $\left.{ }_{2}\right)_{2 \text {-homo }}$ upon mixing, with their own specific features.

To gain more insight in the mixing behavior of $\mathrm{DTS}\left(\mathrm{FBTTh}_{2}\right)_{2}$ and DTS(FBTTh $)_{2}$-homo without $\mathrm{PC}_{71} \mathrm{BM}$, binary mixtures of different mixing ratio were studied by RHC. The mixtures were prepared without DIO as processing additive to avoid uncertainty in the positions of the thermal transitions (vide supra). Figure S12c shows the second heating thermograms for compositions ranging from pure DTS $\left(\mathrm{FBTTh}_{2}\right)_{2}$ (100:0) to pure $\operatorname{DTS}\left(\text { FBTTh }_{2}\right)_{2 \text {-homo }}(0: 100)$. A eutectic phase behavior is observed. DTS(FBTTh $\left.{ }_{2}\right)_{2}$ and DTS(FBTTh $\left.{ }_{2}\right)_{2}$-homo have a narrow melting peak at $207{ }^{\circ} \mathrm{C}$ and $231{ }^{\circ} \mathrm{C}$ and similar melting enthalpies of $42.5 \mathrm{~J} \mathrm{~g}^{-1}$ and $40.5 \mathrm{~J} \mathrm{~g}^{-1}$, respectively. For intermediate compositions, the narrowest melting peak around $196{ }^{\circ} \mathrm{C}$ with a reduced melting enthalpy of $34 \mathrm{~J} \mathrm{~g}^{-1}$ is observed for the 70:30 composition, which should be very close to the eutectic composition. For concentrations $\leq 30 \%$ homocoupled material, eutectic melting in combination with the melting trajectory of pure excess DTS $\left(\mathrm{FBTTh}_{2}\right)_{2}$ is seen. For concentrations $>30 \%$ homocoupled material, eutectic melting followed by the broader melting trajectory of pure excess DTS $\left(\mathrm{FBTTh}_{2}\right)_{2 \text {-homo }}$ is observed. The eutectic composition is the result of specific interactions and is expected to lead to a typical, finely grained (nano)morphology of crystallites of both components. The lower melting enthalpy at the eutectic composition also indicates a lower crystallinity than the pure components. Note that for all binary mixtures no glass transition could be detected. At this stage of investigation, no clear indications are found for the formation of an extra compound (molecular complex). The eutectic behavior of these binary mixtures provides a rationale for the role of homocoupled material on the electro-optical properties (vide supra). The physicochemical properties of possibly formed compounds ('alloys') and their influence on charge transport and formation of traps are subject of a future study.

\section{CONCLUSIONS}

In this work, the origin of the detrimental effect of homocouplings on the photovoltaic device performance has been elucidated by performing a systematic study on a push-pull small molecule system $\left(\right.$ DTS $\left.\left(\text { FBTTh }_{2}\right)_{2}\right)$. Low quantities $(5 \%)$ of homocoupled side product are sufficient to significantly decrease the device performance. The presence of homocoupled side products in a material batch results in a multicomponent solar cell system, which translates itself into a non-optimal morphology at different length scales, strongly affecting all photovoltaic parameters. The presence of homocouplings seems to inherently alter the structural composition of the morphological phases and to reduce the overall crystallinity of the mixtures. Furthermore, we conclude from sensitive photocurrent measurements that it is likely for homocoupled products to form eutectic mixtures with the neat material, thereby reducing the charge carrier mobility only slightly. The configuration of the energy levels of the homocoupled product is, besides the current, of major importance for the open-circuit voltage. In this study it is shown that homocoupling of an electron rich donor unit leads to an increase of the overall HOMO energy level, thereby decreasing the open-circuit voltage.

In general, homocouplings can appear in various push-pull conjugated small molecules and polymers, giving rise to batch-tobatch variation. These side products should always be avoided, either by purification after synthesis or by designing optimal synthetic routes. ${ }^{62}$ The latter obviously has the preference since every purification step will introduce extra costs. ${ }^{62}$ The general message is that the presence of homocouplings strongly impacts the molecular packing of aggregated regions, but also the electronic properties, which can give rise to a significantly reduced device performance. Although the present study focuses on organic solar cells, the results certainly also impact other domains in which these donor-acceptor type low band gap materials have recently taken up a prominent role (e.g. transistors, photodetectors, and bio-imaging applications). ${ }^{64,65}$

\section{EXPERIMENTAL SECTION}

The experimental section can be found in the Supporting Information.

\section{ASSOCIATED CONTENT}

\section{Supporting Information}

More information on the experimental details, overview of homocoupling literature, synthesis protocol of DTS(FBTTh 2$)_{2}$-homo, ${ }^{1} \mathrm{H}$ and ${ }^{13} \mathrm{C}$ NMR spectra, MALDI-TOF mass spectra, photovoltaic parameters, GIWAXS, FTPS-EQE, quantum chemical calculations, cyclic voltammetry, pCELIV, and RHC can be found in the Supporting Information. The Supporting Information is available free of charge on the ACS Publications website.

\section{AUTHOR INFORMATION}

\section{Corresponding Author \\ * tim.vangerven@uhasselt.be}

\section{Author Contributions}

T.V., P.V., W.M., and J.M. designed the study and developed the methodology. T.V. and P.V. wrote the manuscript. P.V. and P.A. performed the chemical synthesis and chemical analysis (NMR, MALDI). J.D. performed the TEM measurements. T.V. and I.C. prepared and optimized the devices. T.V. performed and analyzed the electro-optical measurements (FTPS, EQE, pCELIV, and UV-Vis). K.V. also contributed significantly to the analysis of the FTPS-EQE spectra. J.B. and K.V. performed and analyzed the absolute absorption measurements. N.V.D.B, M.D., and B.V.M. carried out the rapid heat-cool calorimetry 
and thermal analysis. V.L., D.B., R.L., and B.C. performed and analyzed the DFT calculations. N.P., J.W.A., and D.W.B. performed and analyzed the GIWAXS measurements. All authors contributed to the analysis and writing. D.V., W.M., and J.M. supervised the overall project.

\section{ACKNOWLEDGMENT}

The authors thank Hasselt University and the Research Foundation Flanders (FWO) for financial support. The collaboration between Hasselt and Mons is supported by the Science Policy Office of the Belgian Federal Government (BELSPO; IAP 7/05 project FS2). T.V. and M.D. acknowledge the Agency for Innovation by Science and Technology in
Flanders (IWT) for their Ph.D. grant. K.V. and J.B. thank the German Federal Ministry for Education and Research (BMBF) for funding through the InnoProfille project "Organische p-i-n Bauelemente 2.2". The M-ERA.NET project 'RADESOL' is funded under the EU Seventh Framework Programme (FP7/2007-2013), grant agreement no. 234648/O70. J.W.A. acknowledges funding from the European Research Council (ERC) under the European Union's Horizon 2020 research and innovation program (grant agreement No 681881). The authors further acknowledge Huguette Penxten for the CV measurements. The research in Mons is also supported by FNRS-FRFC and the European Commission / Walloon Region (FEDER - BIORGEL project). D.B. is a FNRS Research Director. The authors finally acknowledge TA Instruments for the RHC equipment.

\section{REFERENCES}

(1) Dierckx, W.; Oosterbaan, W. D.; Bolsée, J.-C.; Cardinaletti, I.; Maes, W.; Boyen, H.-G.; D’Haen, J.; Nesladek, M.; Manca, J. Organic Phototransistors Using poly(3-Hexylthiophene) Nanofibres. Nanotechnology 2015, 26 (6), 65201.

(2) Zhang, H.; Jenatsch, S.; De Jonghe, J.; Nüesch, F.; Steim, R.; Véron, A. C.; Hany, R. Transparent Organic Photodetector Using a near-Infrared Absorbing Cyanine Dye. Sci. Rep. 2015, 5, 9439.

(3) Klauk, H. Organic Thin-Film Transistors. Chem. Soc. Rev. 2010, 39 (7), 2643-2666.

(4) Fyfe, D. LED Technology: Organic Displays Come of Age. Nat. Photonics 2009, 3 (8), $453-455$.

(5) Zhao, J.; Li, Y.; Yang, G.; Jiang, K.; Lin, H.; Ade, H.; Ma, W.; Yan, H. Efficient Organic Solar Cells Processed from Hydrocarbon Solvents. Nat. Energy 2016, 1, 15027.

(6) Li, S.; Ye, L.; Zhao, W.; Zhang, S.; Mukherjee, S.; Ade, H.; Hou, J. Energy-Level Modulation of Small-Molecule Electron Acceptors to Achieve over 12\% Efficiency in Polymer Solar Cells. Adv. Mater. 2016, 28 (42), 9423-9429.

(7) Brouwer, F.; Alma, J.; Valkenier, H.; Voortman, T. P.; Hillebrand, J.; Chiechi, R. C.; Hummelen, J. C. Using Bis(pinacolato)diboron to Improve the Quality of Regioregular Conjugated Co-Polymers. J. Mater. Chem. 2011, 21 (5), $1582-1592$.

(8) Chen, C. M.; Jen, T. H.; Chen, S. A. Effective End Group Modification of Poly(3-Hexylthiophene) with Functional ElectronDeficient Moieties for Performance Improvement in Polymer Solar Cell. ACS Appl. Mater. Interfaces 2015, 7 (37), 2054820555.

(9) Heintges, G. H. L.; van Franeker, J. J.; Wienk, M. M.; Janssen, R. A. J. The Effect of Branching in a Semiconducting Polymer on the Efficiency of Organic Photovoltaic Cells. Chem. Commun. 2016, 52 (1), 92-95.

(10) Nikiforov, M. P.; Lai, B.; Chen, W.; Chen, S.; Schaller, R. D.; Strzalka, J.; Maser, J.; Darling, S. B. Detection and Role of Trace Impurities in High-Performance Organic Solar Cells. Energy Environ. Sci. 2013, 6 (5), 1513-1520.

(11) Katsouras, A.; Gasparini, N.; Koulogiannis, C.; Spanos, M.; Ameri, T.; Brabec, C. J.; Chochos, C. L.; Avgeropoulos, A. Systematic Analysis of Polymer Molecular Weight Influence on the Organic Photovoltaic Performance. Macromol. Rapid Commun. 2015, $36(20), 1778-1797$. 
Anthopoulos, T. D.; Durrant, J. R.; McCulloch, I. The Influence of Polymer Purification on Photovoltaic Device Performance of a Series of Indacenodithiophene Donor Polymers. Adv. Mater. 2013, 25 (14), 2029-2034.

(13) Mateker, W. R.; Douglas, J. D.; Cabanetos, C.; Sachs-Quintana, I. T.; Bartelt, J. A.; Hoke, E. T.; El Labban, A.; Beaujuge, P. M.; Fréchet, J. M. J.; McGehee, M. D. Improving the Long-Term Stability of PBDTTPD Polymer Solar Cells through Material Purification Aimed at Removing Organic Impurities. Energy Environ. Sci. 2013, 6 (8), 2529-2537.

(14) Kong, J.; Song, S.; Yoo, M.; Lee, G. Y.; Kwon, O.; Park, J. K.; Back, H.; Kim, G.; Lee, S. H.; Suh, H.; Lee, K. Long-Term Stable Polymer Solar Cells with Significantly Reduced Burn-in Loss. Nat. Commun. 2014, 5, 5688.

(15) Carsten, B.; He, F.; Son, H. J.; Xu, T.; Yu, L. Stille Polycondensation for Synthesis of Functional Materials. Chem. Rev. 2011, $111(3), 1493-1528$.

(16) Vangerven, T.; Verstappen, P.; Drijkoningen, J.; Dierckx, W.; Himmelberger, S.; Salleo, A.; Vanderzande, D.; Maes, W.; Manca, J. V. Molar Mass versus Polymer Solar Cell Performance: Highlighting the Role of Homocouplings. Chem. Mater. 2015, 27 (10), 3726-3732.

(17) Lu, L.; Zheng, T.; Xu, T.; Zhao, D.; Yu, L. Mechanistic Studies of Effect of Dispersity on the Photovoltaic Performance of PTB7 Polymer Solar Cells. Chem. Mater. 2015, 27 (2), 537-543.

(18) Hendriks, K. H.; Li, W.; Heintges, G. H. L.; van Pruissen, G. W. P.; Wienk, M. M.; Janssen, R. A. J. Homocoupling Defects in Diketopyrrolopyrrole-Based Copolymers and Their Effect on Photovoltaic Performance. J. Am. Chem. Soc. 2014, 136 (31), 11128-11133.

(19) Chen, S.; Lee, K. C.; Zhang, Z.-G.; Kim, D. S.; Li, Y.; Yang, C. An Indacenodithiophene-Quinoxaline Polymer Prepared by Direct Arylation Polymerization for Organic Photovoltaics. Macromolecules 2016, 49 (2), 527-536.

(20) Wakioka, M.; Ishiki, S.; Ozawa, F. Synthesis of Donor-Acceptor Polymers Containing Thiazolo[5,4- $d$ ]thiazole Units via Palladium-Catalyzed Direct Arylation Polymerization. Macromolecules 2015, 48 (22), 8382-8388.

(21) Chang, S.-W.; Kettle, J.; Waters, H.; Horie, M. Cyclopentadithiophene-Benzothiadiazole Copolymers with Permutations of Repeating Unit Length and Ratios; Synthesis, Optical and Electrochemical Properties and Photovoltaic Characteristics. RSC $A d v .2015,5$ (130), 107276-107284.

(22) Carsten, B.; Szarko, J. M.; Son, H. J.; Wang, W.; Lu, L.; He, F.; Rolczynski, B. S.; Lou, S. J.; Chen, L. X.; Yu, L. Examining the Effect of the Dipole Moment on Charge Separation in Donor-Acceptor Polymers for Organic Photovoltaic Applications. J. Am. Chem. Soc. 2011, 133 (50), 20468-20475.

(23) Lombeck, F.; Komber, H.; Fazzi, D.; Nava, D.; Kuhlmann, J.; Stegerer, D.; Strassel, K.; Brandt, J.; de Zerio Mendaza, A. D.; Müller, C.; Thiel, W.; Caironi, M.; Friend, R.; Sommer, M. On the Effect of Prevalent Carbazole Homocoupling Defects on the Photovoltaic Performance of PCDTBT:PC 71 BM Solar Cells. Adv. Energy Mater. 2016, 1601232. 
Welch, G. C.; Perez, L. A.; Hoven, C. V.; Zhang, Y.; Dang, X.-D.; Sharenko, A.; Toney, M. F.; Kramer, E. J.; Nguyen, T.Q.; Bazan, G. C. A Modular Molecular Framework for Utility in Small-Molecule Solution-Processed Organic Photovoltaic Devices. J. Mater. Chem. 2011, 21 (34), 12700-12709.

Kan, B.; Zhang, Q.; Li, M.; Wan, X.; Ni, W.; Long, G.; Wang, Y.; Yang, X.; Feng, H.; Chen, Y. Solution-Processed Organic Solar Cells Based on Dialkylthiol-Substituted Benzodithiophene Unit with Efficiency near 10\%. J. Am. Chem. Soc. 2014, $136(44), 15529-15532$.

(26) Kan, B.; Li, M.; Zhang, Q.; Liu, F.; Wan, X.; Wang, Y.; Ni, W.; Long, G.; Yang, X.; Feng, H.; Zuo, Y.; Zhang, M.; Huang, F.; Cao, Y.; Russell, T. P.; Chen, Y. A Series of Simple Oligomer-like Small Molecules Based on Oligothiophenes for Solution-Processed Solar Cells with High Efficiency. J. Am. Chem. Soc. 2015, 137 (11), 3886-3893.

Kudrjasova, J.; Kesters, J.; Verstappen, P.; Brebels, J.; Vangerven, T.; Cardinaletti, I.; Drijkoningen, J.; Penxten, H.; Manca, J.; Lutsen, L.; Vanderzande, D.; Maes, W. A Direct Arylation Approach towards Efficient Small Molecule Organic Solar Cells. J. Mater. Chem. A 2015, 4 (II), 791-795.

(28) Verstappen, P.; Cardinaletti, I.; Vangerven, T.; Vanormelingen, W.; Verstraeten, F.; Lutsen, L.; Vanderzande, D.; Manca, J.; Maes, W. Impact of Structure and Homo-Coupling of the Central Donor Unit of Small Molecule Organic Semiconductors on Solar Cell Performance. RSC Adv. 2016, 6 (38), 32298-32307.

(29) Van Der Poll, T.S.; Love, J.A.; Nguyen, T.Q.; Bazan, G.C. Non-Basic High-Performance Molecules for Solution-Processed Organic Solar Cells. Adv. Mater. 2012, 24, 3646-3649.

(30) Ma, W.; Tumbleston, J. R.; Wang, M.; Gann, E.; Huang, F.; Ade, H. Domain Purity, Miscibility, and Molecular Orientation at Donor/Acceptor Interfaces in High Performance Organic Solar Cells: Paths to Further Improvement. Adv. Energy Mater. 2013, 3 (7), 864-872.

(31) Collins, B. A.; Tumbleston, J. R.; Ade, H. Miscibility, Crystallinity, and Phase Development in P3HT/PCBM Solar Cells: Toward an Enlightened Understanding of Device Morphology and Stability. J. Phys. Chem. Lett. 2011, 2 (24), 3135-3145.

Razzell-Hollis, J.; Limbu, S.; Kim, J. Spectroscopic Investigations of Three-Phase Morphology Evolution in Polymer: Fullerene Solar Cell Blends. J. Phys. Chem. C 2016, 120 (20), 10806-10814.

Sweetnam, S.; Graham, K. R.; Ngongang Ndjawa, G. O.; Heumüller, T.; Bartelt, J. A.; Burke, T. M.; Li, W.; You, W.; Amassian, A.; McGehee, M. D. Characterization of the Polymer Energy Landscape in Polymer:Fullerene Bulk Heterojunctions with Pure and Mixed Phases. J. Am. Chem. Soc. 2014, 136 (40), 14078-14088.

(34) Burke, T. M.; McGehee, M. D. How High Local Charge Carrier Mobility and an Energy Cascade in a Three-Phase Bulk Heterojunction Enable >90\% Quantum Efficiency. Adv. Mater. 2014, 26 (12), 1923-1928.

(35) Jamieson, F. C.; Domingo, E. B.; McCarthy-Ward, T.; Heeney, M.; Stingelin, N.; Durrant, J. R. Fullerene Crystallisation as a Key Driver of Charge Separation in Polymer/fullerene Bulk Heterojunction Solar Cells. Chem. Sci. 2012, 3 (2), 485-492. 
Love, J. A.; Proctor, C. M.; Liu, J.; Takacs, C. J.; Sharenko, A.; Van Der Poll, T. S.; Heeger, A. J.; Bazan, G. C.; Nguyen, T. Q. Film Morphology of High Efficiency Solution-Processed Small-Molecule Solar Cells. Adv. Funct. Mater. 2013, 23 (40), 5019-5026.

(38) Sirringhaus, H.; Brown, P. J.; Friend, R. H.; Nielsen, M. M.; Bechgaard, K.; Langeveld-Voss, B. M. W.; Spiering, A. J. H.; Janssen, R. A. J.; Meijer, E. W.; Herwig, P.; de Leeuw, D. M. Two-Dimensional Charge Transport in Self-Organized, HighMobility Conjugated Polymers. Nature 1999, 401 (6754), 685-688.

Breiby, D. W.; Bunk, O.; Andreasen, J. W.; Lemke, H. T.; Nielsen, M. M. Simulating X-Ray Diffraction of Textured Films. J. Appl. Crystallogr. 2008, 41 (2), 262-271.

(40) Breiby, D. W.; Chin, P. T. K.; Andreasen, J. W.; Grimsrud, K. A.; Di, Z.; Janssen, R. A. J. Biaxially Oriented CdSe Nanorods. Langmuir 2009, 25 (18), 10970-10974.

(41) Breiby, D. W.; Sato, S.; Samuelsen, E. J.; Mizoguchi, K. Electron Spin Resonance Studies of Anisotropy in Semiconducting Polymeric Films. J. Polym. Sci. Part B Polym. Phys. 2003, 41 (23), 3011-3025.

(42) Kesava, S.V.; Fei, F.; Rimshaw, A. D.; Wang, C.; Hexemer, A.; Asbury, J.B.; Heeney, M.; Gomez, E. D. Solar Cells: Domain Compositions and Fullerene Aggregation Govern Charge Photogeneration in Polymer/Fullerene Solar Cells. Adv. Energy Mater. 2014, 4, 1400116.

(43) Golubovic, L.; Moldovan, D.; Peredera, A. Flexible Polymers and Thin Rods far from Equilibrium: Buckling Dynamics. Phys. Rev. E 2000, 61 (2), 1703-1715.

(44) Verstappen, P.; Kesters, J.; D’Olieslaeger, L.; Drijkoningen, J.; Cardinaletti, I.; Vangerven, T.; Bruijnaers, B. J.; Willems, R. E. M.; D’Haen, J.; Manca, J. V.; Lutsen, L.; Vanderzande, D. J. M.; Maes, W. Simultaneous Enhancement of Solar Cell Efficiency and Stability by Reducing the Side Chain Density on Fluorinated PCPDTQx Copolymers. Macromolecules 2015, 48 (12), 3873-3882.

(45) Wolf, J.; Babics, M.; Wang, K.; Saleem, Q.; Liang, R.; Hansen, M. R.; Beaujuge, P. M. Benzo[1,2-b:4,5-b']dithiophenePyrido[3,4-b]Pyrazine Small-Molecule Donors for Bulk Heterojunction Solar Cells. Chem. Mater. 2016, 28 (7), $2058-2066$.

(46) Spoltore, D.; Vangerven, T.; Verstappen, P.; Piersimoni, F.; Bertho, S.; Vandewal, K.; Van den Brande, N.; Van Mele, B.; De Sio, A.; Parisi, J.; Lutsen, L.; Vanderzande, D.; Maes, W.; Manca, J. V. Effect of Molecular Weight on Morphology and Photovoltaic Properties in P3HT:PCBM Solar Cells. Org. Electron. 2015, 21, 160-170.

(47) Yang, L.; Zhou, H.; Price, S. C.; You, W. Parallel-like Bulk Heterojunction Polymer Solar Cells. J. Am. Chem. Soc. 2012, 134 (12), 5432-5435. 

Bulk Heterojunction Solar Cells Based on Two Donor Polymers. J. Am. Chem. Soc. 2012, 134 (22), 9074-9077. Street, R. A.; Khlyabich, P. P.; Rudenko, A. E.; Thompson, B. C. Electronic States in Dilute Ternary Blend Organic Bulk Heterojunction Solar Cells. J. Phys. Chem. C 2014, 118 (46), 26569-26576.

(50) Lu, L.; Chen, W.; Xu, T.; Yu, L. High-Performance Ternary Blend Polymer Solar Cells Involving Both Energy Transfer and Hole Relay Processes. Nat. Commun. 2015, 6, 7327.

(51) Mollinger, S. A.; Vandewal, K.; Salleo, A. Microstructural and Electronic Origins of Open-Circuit Voltage Tuning in Organic Solar Cells Based on Ternary Blends. Adv. Energy Mater. 2015, 5 (23), 1501335.

(52) Vandewal, K. Interfacial Charge Transfer States in Condensed Phase Systems. Annu. Rev. Phys. Chem. 2016, 67 (1), 113133.

(53) Vandewal, K.; Tvingstedt, K.; Gadisa, A.; Inganäs, O.; Manca, J. V. On the Origin of the Open-Circuit Voltage of PolymerFullerene Solar Cells. Nat. Mater. 2009, 8 (11), 904-909.

(54) Scharber, M. C. On the Efficiency Limit of Conjugated Polymer:Fullerene-Based Bulk Heterojunction Solar Cells. Adv. Mater. 2016, 28 (10), 1994-2001.

(55) Kouijzer, S.; Wei Wei, L.; Wienk, M. M.; Janssen, R. A. J. Charge Transfer State Energy in Ternary Bulk-heterojunction Polymer-fullerene Solar Cells. J. Photon. Energy 2015, 5 (1), 057203

(56) Danley, R. L.; Caulfield, P. A.; Aubuchon, S. R. A Rapid-Scanning Differential Scanning Calorimeter. Am. Lab. 2008, 40, $9-11$.

(57) Wouters, S.; Demir, F.; Beenaerts, L.; Van Assche, G. Calibration and performance of a fast-scanning DSC-Project RHC. Thermochim. Acta 2012, 530, 64-72.

(58) Koningsveld, R.; Stockmayer, W. H.; Nies, E. Polymer phase diagrams. A textbook, Oxford University Press, Oxford, New York, 2001.

(59) Zhang, J.; Zhang, Y.; Fang, J.; Lu, K.; Wang, Z.; Ma, W.; Wei, Z. Conjugated Polymer-Small Molecule Alloy Leads to High Efficient Ternary Organic Solar Cells. J. Am. Chem. Soc. 2015, 137 (25), 8176-8183.

(60) Street, R. A.; Davies, D.; Khlyabich, P. P.; Burkhart, B.; Thompson, B. C. Origin of the Tunable Open-Circuit Voltage in Ternary Blend Bulk Heterojunction Organic Solar Cells. J. Am. Chem. Soc. 2013, 135 (3), 986-989.

(61) Pivrikas, A.; Sariciftci, N. S.; Juška, G.; Österbacka, R. A Review of Charge Transport and Recombination in Polymer/fullerene Organic Solar Cells. Prog. Photovoltaics Res. Appl. 2007, 15 (8), 677-696.

(62) Rudenko, A. E.; Thompson, B. C. Optimization of Direct Arylation Polymerization (DArP) through the Identification and Control of Defects in Polymer Structure. J. Polym. Sci. Part A Polym. Chem. 2015, 53 (2), 135-147.

(63) Osedach, T. P.; Andrew, T. L.; Bulović, V. Effect of Synthetic Accessibility on the Commercial Viability of Organic Photovoltaics. Energy Environ. Sci. 2013, 6 (3), 711-718. 
(64) Li, K.; Liu, B. Polymer-Encapsulated Organic Nanoparticles for Fluorescence and Photoacoustic Imaging. Chem. Soc. Rev. 2014, 43 (18), 6570-6597.

(65) Dou, L.; Liu, Y.; Hong, Z.; Li, G.; Yang, Y. Low-Bandgap Near-IR Conjugated Polymers/Molecules for Organic Electronics. Chem. Rev. 2015, 115 (23), 12633-12665. 
TOC graphic

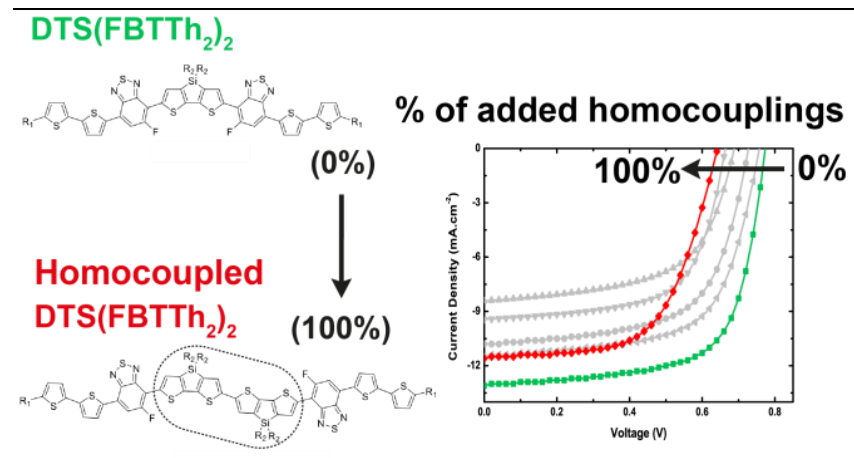

